\title{
Ceramics
}

\section{Mechanochemical synthesis: route to novel rock-salt- structured high-entropy oxides and oxyfluorides}

Ling Lin ${ }^{1}$ (D), Kai Wang ${ }^{2}$, Raheleh Azmi $^{3}$ (D), Junbo Wang ${ }^{1}$ (D), Abhishek Sarkar ${ }^{1,4}$ (D), Miriam Botros ${ }^{1}$ (D), Saleem Najib ${ }^{5}$, Yanyan Cui ${ }^{1}$, David Stenzel ${ }^{1}$ (D), Parvathy Anitha Sukkurji ${ }^{1}$ (D), Qingsong Wang ${ }^{1}$ (D), Horst Hahn ${ }^{1,4,6}$ (D), Simon Schweidler ${ }^{1, *}$ (D), and Ben Breitung ${ }^{1, \star}$ (B)

${ }^{1}$ Institute of Nanotechnology, Karlsruhe Institute of Technology (KIT), Hermann-von-Helmholtz-Platz 1, 76344 Eggenstein-Leopoldshafen, Germany

${ }^{2}$ Department of Materials and Earth Sciences, Technische Universität Darmstadt, Alarich-Weiss-Str. 2, 64287 Darmstadt, Germany

${ }^{3}$ Institute for Applied Materials, Karlsruhe Institute of Technology (KIT), Hermann-von-Helmholtz-Platz 1, 76344 Eggenstein-Leopoldshafen, Germany

${ }^{4}$ Joint Research Laboratory Nanomaterials, Technische Universität Darmstadt and Karlsruhe Institute of Technology (KIT), OttoBerndt-Str. 3, 64206 Darmstadt, Germany

${ }^{5}$ Faculty of Engineering, University of Waterloo, 200 University Avenue West, Waterloo, ON N2L 3G1, Canada

${ }^{6}$ Helmholtz Institute Ulm for Electrochemical Energy Storage, Helmholtzstr. 11, 89081 Ulm, Germany

Received: 9 June 2020

Accepted: 29 August 2020

Published online:

14 September 2020

(C) The Author(s) 2020

\begin{abstract}
A facile mechanochemical reaction at ambient temperature was successfully applied to synthesize novel single-phase rock-salt-structured high-entropy oxides, containing five, six and seven metal elements in equiatomic amounts. This synthesis approach overcomes the limitations of the commonly known synthesis procedures, which would result in multiple-phase compounds. Redox-sensitive elements, such as $\mathrm{Fe}^{2+}$ and $\mathrm{Mn}^{2+}$, can now be considered. The corresponding single-phase Li-containing high-entropy oxyfluorides were obtained by introducing LiF into the lattice using the same strategy. All materials show single-phase rock-salt structures with lattice parameters depending on the incorporated ion sizes. Solid solution states result in high configurational entropies, and all elements appear homogenously distributed over the whole cationic and anionic sublattice. The straightforward synthesis technique, combined with utilized simple binary oxide precursors, paves the way for a multitude of novel high-entropy oxide and oxyfluoride compounds. The compounds were studied by means of X-ray diffraction, transmission electron microscopy, energy-dispersive X-ray spectroscopy and Mössbauer spectroscopy.
\end{abstract}

Handling Editor: M. Grant Norton.

Address correspondence to E-mail: simon.schweidler@kit.edu; ben.breitung@kit.edu 


\section{Introduction}

In recent years, a new class of materials enjoys rising popularity, which is based on an entropy stabilization of the crystal structure and related to the socalled high-entropy materials (HEMs) [1]. These HEMs utilize a promising concept to form singlephase compounds composed of a multitude of different elements. This variety of elements leads to a high configurational entropy, which counteracts segregation or separation of the individual components, and the single-phase material can show a crystal structure that differs from the typical structures of the constituent elements. The high-entropy concept was first applied to alloy systems, but later introduced into ceramics. The configurational entropy $\left(S_{\text {config }}\right)$ is solely dependent on the number of different elements and their stoichiometry $\left(x_{i}\right.$ and $\left.x_{j}\right)$ in the cationic or anionic sublattice $(N, M$, for ionic compounds) and follows Boltzmann's entropy formula (Eq. 1) [2, 3]. $R$ describes the ideal gas constant.

$S_{\text {config }}=-R\left[\left(\sum_{i=1}^{N} x_{i} \ln x_{i}\right)_{\text {cation-site }}+\left(\sum_{j=1}^{M} x_{j} \ln x_{j}\right)_{\text {anion-site }}\right]$.

The interactions originating from different elements incorporated in a single-phase structure, combined with the structural stabilization derived from the high configurational entropy, endow these materials with exciting and unexpected properties [2-8]. A similar class of materials, for which entropy stabilization has been reported, are the so-called cation-disordered rock-salt transition metal oxides (DRX) $[9,10]$. Here, the entropy deriving from the introduction of different cations into the crystal lattice promotes the disorder of the compounds and avoids agglomerations of similar elements. Usually, they contain less cations than a high-entropy material, so the configurational entropy is below 1.5 $R$. Additionally, the lower number of elements decreases the interactions between the incorporated species, which are known as "cocktail effects" for high-entropy materials. These DRX materials are often used as cathode active materials and show exceptional capacities [11-13].

In 2015, Rost et al. reported for the first time on high-entropy oxides (HEOs) and could show indications for an entropy stabilization of the crystal structure [3]. This system contained divalent $\mathrm{Co}, \mathrm{Cu}$, $\mathrm{Mg}, \mathrm{Ni}, \mathrm{Zn}$ in equimolar amounts and formed the single-phase rock-salt structure $\left(\mathrm{Co}_{0.2} \mathrm{Cu}_{0.2} \mathrm{Mg}_{0.2-}\right.$ $\left.\mathrm{Ni}_{0.2} \mathrm{Zn}_{0.2}\right) \mathrm{O}$. This initial study led to an increased activity on the field of oxide type high-entropy compounds, resulting in a multitude of different structures incorporating various elements. Recent studies report on the successful synthesis of fluoritetype HEOs [14-17], e.g., $\left(\mathrm{Ce}_{0.2} \mathrm{Zr}_{0.2} \mathrm{Hf}_{0.2} \mathrm{Sn}_{0.2} \mathrm{Ti}_{0.2}\right) \mathrm{O}_{2}$, perovskite-type HEOs [18-20], e.g., $\left(\mathrm{Gd}_{0.2} \mathrm{La}_{0.2} \mathrm{Nd}_{0.2}\right.$ $\left.\mathrm{Sm}_{0.2} \mathrm{Y}_{0.2}\right)\left(\mathrm{Co}_{0.2} \mathrm{Cr}_{0.2} \mathrm{Fe}_{0.2} \mathrm{Mn}_{0.2} \mathrm{Ni}_{0.2}\right) \mathrm{O}_{3}$, and spineltype HEOs [21], e.g., $\left(\mathrm{Co}_{0.2} \mathrm{Cr}_{0.2} \mathrm{Fe}_{0.2} \mathrm{Mn}_{0.2} \mathrm{Ni}_{0.2}\right)_{3} \mathrm{O}_{4}$.

Although these crystal structures have been explored, there are impediments, which limit the choice of elements to form single-phase structures, and to date not all have been explained. This restricts the versatility to alter the compositions and thereby the properties of the compounds. For the mentioned rock-salt-structured high-entropy oxide $\left(\mathrm{Co}_{0.2} \mathrm{Cu}_{0.2-}\right.$ $\left.\mathrm{Mg}_{0.2} \mathrm{Ni}_{0.2} \mathrm{Zn}_{0.2}\right) \mathrm{O}$, it is difficult to replace elements, since then often secondary phases are formed. Some examples and workarounds were found to enable the synthesis of single-phased rock-salt structures $[6,22,23]$, like doping a low amount of additional elements or adding monovalent $\mathrm{Li}^{+}$to compensate higher valent transition metals like $\mathrm{Fe}^{3+}$ or $\mathrm{Cr}^{3+}$. Nevertheless, until now, it was not possible to prepare other single-phased rock-salt structures than $\left(\mathrm{Co}_{0.2} \mathrm{Cu}_{0.2} \mathrm{Mg}_{0.2} \mathrm{Ni}_{0.2} \mathrm{Zn}_{0.2}\right) \mathrm{O}$ with an equimolar cation ratio, or to increase the amount of cations, without introducing alkaline cations for charge neutrality [22].

The common HEO synthesis procedures, such as nebulized spray pyrolysis (NSP), flame spray pyrolysis (FSP), reverse co-precipitation (RCP), hydrothermal (HT) and solution combustion synthesis (SCS) $[2,15,17,18,24-27]$, undergo a high-temperature step or need precursors that are stable in solution and in air, so that they are often not suitable for air-sensitive or thermally unstable ions. As an example, NSP can be used for preparation of single-phased rock-salt $\left(\mathrm{Co}_{0.2} \mathrm{Cu}_{0.2} \mathrm{Mg}_{0.2} \mathrm{Ni}_{0.2} \mathrm{Zn}_{0.2}\right) \mathrm{O}$, but when incorporating $\mathrm{Fe}$ or $\mathrm{Mn}$ precursors, these elements will not only form $2+$ species as needed for rock-salt structures, but oxidize to higher valence ions. Therefore, when incorporating $\mathrm{Fe}$ or $\mathrm{Mn}$ precursors with NSP in equimolar amounts to the other cations, secondary mixed valence spinel phases occur (rock-salt: $2+$ cations, spinel: $2+$ and $3+$ cations). To counter the secondary phase formation, often $\mathrm{Li}^{+}$ 
is introduced to compensate the $3+$ charge in rocksalt structures.

In this report, we present the synthesis and characterization of four novel rock-salt high-entropy oxides (HEOs) and additionally their transfer to singlephase multi-anionic oxyfluoride systems (Li(HEO)Fs). These HEOs contain different elements than the already reported compound $\left(\mathrm{Co}_{0.2} \mathrm{Cu}_{0.2-}\right.$ $\left.\mathrm{Mg}_{0.2} \mathrm{Ni}_{0.2} \mathrm{Zn}_{0.2}\right) \mathrm{O}$ in equimolar ratios and two of them even incorporate 6 and 7 different equimolar cations. They all show a phase-pure rock-salt structure, and all metal ions, except $\mathrm{Li}^{+}$, maintain divalent during the synthesis process. A subsequent internal disproportionation of the ions can appear, but keeping the charge balance of the compound and therefore the structure intact. From our experience, this is the crucial step to maintain the rock-salt structure and to inhibit the formation of additional phases. The new high-entropy materials were characterized comprehensively using $\mathrm{X}$-ray diffraction, transmission electron microscopy, energy-dispersive $X$-ray and Mössbauer spectroscopy. This work provides a simple approach to synthesize high-entropy materials, even if the materials contain air-sensitive or thermally unstable ions.

\section{Materials and methods}

\section{Synthesis}

All chemicals were purchased from commercial sources (Sigma-Aldrich/Alfa Aesar/ABCR GmbH, purity $\geq 99 \%$ ) and used without further purification.

For the synthesis of HEOs, divalent metal oxides powders ( $\mathrm{ZnO}, \mathrm{CuO}, \mathrm{MnO}, \mathrm{FeO}, \mathrm{NiO}, \mathrm{CoO}, \mathrm{MgO}$ ) were used. Equal molar ratio of corresponding oxides was mixed and ball milled at $500 \mathrm{rpm}$ for $12 \mathrm{~h}$ in a high-purity argon gas, using a high-energy planetary ball-milling machine (Retsch PM 100, Retsch GmbH). The ball-to-powder weight ratio was 40:1. WC vials (50 $\mathrm{ml}$ in volume) and WC balls (4 $\mathrm{mm}$ in diameter) were used. All $\mathrm{Li}(\mathrm{HEO}) \mathrm{Fs}$ were prepared via $24 \mathrm{~h}$ of ball-milling, with 1: 1 molar ratio of LiF and HEO, according to the literature [28].

Nebulized spray pyrolysis (NSP) method was done as explained in a reported process [24]. For ( $\mathrm{ZnNi}$ $\mathrm{CoMnCu}) \mathrm{O} 5$-cation system, the metal salts dissolved in precursor solution were corresponding nitrates: $\left(\mathrm{Co}\left(\mathrm{NO}_{3}\right)_{2} \cdot 6 \mathrm{H}_{2} \mathrm{O}\right.$,
$\mathrm{Mn}\left(\mathrm{NO}_{3}\right)_{2} \cdot 4 \mathrm{H}_{2} \mathrm{O}, \quad \mathrm{Ni}\left(\mathrm{NO}_{3}\right)_{2} \cdot 6 \mathrm{H}_{2} \mathrm{O}$ and $\mathrm{Zn}\left(\mathrm{NO}_{3}\right)_{2-}$ $6 \mathrm{H}_{2} \mathrm{O}$ (all ABCR $\mathrm{GmbH}$, purity $\geq 98 \%$ ).

\section{Characterization}

XRD patterns were collected on powder samples at room temperature, using a STOE Stadi $P$ diffractometer, equipped with a Ga-jet X-ray source (Ga-K $\beta$ radiation, $1.2079 \AA$ ). Patterns were collected between $2 \theta=20^{\circ}$ and $90^{\circ}$ with a step size of $0.1^{\circ}$ at a scanning rate of $4 \mathrm{~s}$ per step. Refinement of the XRD pattern was performed using TOPAS Academics V5 software. Si served as a calibration sample to determine the instrumental resolution. Background refinement was done using a linear interpolation function comprising 36 parameters.

${ }^{57} \mathrm{Fe}$ Mössbauer spectroscopy was conducted using a spectrometer in transmission geometry with a moving source of ${ }^{57} \mathrm{Co}$ in a Rh matrix and a triangular velocity variation. The isomer shift is given relative to bcc-Fe at room temperature.

TEM measurements (SAED, HR-TEM and STEMEDX) were performed on a FEI Titan 80-300 microscope, equipped with a CEOS image spherical aberration corrector, a HAADF STEM detector (Fischione model 3000), EDAX SUTW EDX detector and a Tridiem Gatan image filter. The microscope was conducted at an accelerating voltage of $300 \mathrm{kV}$. The powder samples were dispersed on a holey carboncoated gold grid and loaded onto an FEI double-tilt holder.

X-ray photoelectron spectroscopy (XPS) measurements were performed on a K-Alpha + instrument (Thermo Fisher Scientific) with a monochromatic Al$\mathrm{K} \alpha$ X-ray source $(1486.6 \mathrm{eV})$ and $400 \mu \mathrm{m}$ spot size. The K-Alpha + charge compensation system was applied to prevent localized charge buildup during analysis using $8 \mathrm{eV}$ electrons and low-energy Ar ions. Data acquisition and processing were carried out using the Thermo Avantage software [29]. The spectra were fitted with one or more Voigt profiles. The binding energies are reported concerning the $\mathrm{C}$ $1 s$ peak of hydrocarbons at $285.0 \mathrm{eV}$. The analyzer transmission function, Scofield sensitivity factors [30] and effective attenuation lengths (EALs) for photoelectrons were applied for quantification. EALs were calculated using the standard TPP-2 M formalism [31]. 


\section{Results and discussion}

Herein, we report on the successful synthesis of rocksalt-structured HEOs with novel combinations of cations and without $\mathrm{Li}^{+}$for charge compensation. The HEOs were synthesized using a facile one-step high-energy ball-milling process in inert atmosphere (argon) at room temperature. Equimolar proportions of divalent metal oxides were used as reactants. Metal ions with similar radii [32] $\left(\mathrm{Fe}^{2+}, \mathrm{Mn}^{2+}, \mathrm{Ni}^{2+}\right.$, $\mathrm{Co}^{2+}, \mathrm{Mg}^{2+}, \mathrm{Cu}^{2+}, \mathrm{Zn}^{2+}$ ) were chosen to form singlephase 5, 6 and 7 cationic systems. The HEOs, namely $\left(\mathrm{Zn}_{0.2} \mathrm{Ni}_{0.2} \mathrm{Co}_{0.2} \mathrm{Mn}_{0.2} \mathrm{Cu}_{0.2}\right) \mathrm{O}, \quad\left(\mathrm{Zn}_{0.2} \mathrm{Ni}_{0.2} \mathrm{Co}_{0.2} \mathrm{Mn}_{0.2-}\right.$ $\left.\mathrm{Fe}_{0.2}\right) \mathrm{O}$, $\left(\mathrm{Zn}_{0.17} \mathrm{Ni}_{0.17} \mathrm{Co}_{0.17} \mathrm{Mn}_{0.17} \mathrm{Fe}_{0.17} \mathrm{Cu}_{0.17}\right) \mathrm{O}$ and $\left(\mathrm{Zn}_{0.14} \mathrm{Ni}_{0.14} \mathrm{Co}_{0.14} \mathrm{Mn}_{0.14} \mathrm{Fe}_{0.14} \mathrm{Cu}_{0.14} \mathrm{Mg}_{0.14}\right) \mathrm{O}$, are later referred to as: HEO-5M1, HEO-5M2, HEO-6M and HEO-7M, respectively. Additionally, following an already reported mechanochemical process for highentropy oxyfluorides (HEOFs) [28], the Li(HEO)Fs were synthesized with similar cation mixture, namely $\mathrm{Li}\left(\mathrm{Zn}_{0.2} \mathrm{Ni}_{0.2} \mathrm{Co}_{0.2} \mathrm{Mn}_{0.2} \mathrm{Cu}_{0.2}\right) \mathrm{OF}, \quad \mathrm{Li}\left(\mathrm{Zn}_{0.2} \mathrm{Ni}_{0.2} \mathrm{Co}_{0.2-}\right.$ $\left.\mathrm{Mn}_{0.2} \mathrm{Fe}_{0.2}\right) \mathrm{OF}, \quad \mathrm{Li}\left(\mathrm{Zn}_{0.17} \mathrm{Ni}_{0.17} \mathrm{Co}_{0.17} \mathrm{Mn}_{0.17} \mathrm{Fe}_{0.17-}\right.$ $\left.\mathrm{Cu}_{0.17}\right) \mathrm{OF}$ and $\mathrm{Li}\left(\mathrm{Zn}_{0.14} \mathrm{Ni}_{0.14} \mathrm{Co}_{0.14} \mathrm{Mn}_{0.14} \mathrm{Fe}_{0.14} \mathrm{Cu}_{0.14} \mathrm{Mg}_{0.14}\right)$ OF (later referred to as LiHEOF-5M1, LiHEOF-5M2, LiHEOF$6 \mathrm{M}$ and LiHEOF-7M, respectively). The configurational entropy $\left(S_{\text {config }}\right)$ acquired by Boltzmann's entropy formula (Eq. 1) is $S_{\text {config }}(\mathrm{HEO}-5 \mathrm{M} 1, \mathrm{HEO}-$ $5 \mathrm{M} 2)=1.61 R, S_{\text {config }}(\mathrm{HEO}-6 \mathrm{M})=1.79 R, S_{\text {config }}(\mathrm{HEO}-$ $7 \mathrm{M})=1.95 R, \quad S_{\text {config }}($ LiHEOF-5M1, LiHEOF$5 \mathrm{M} 2)=2.19 R, \quad S_{\text {config }}($ LiHEOF-6M $)=2.28 R, \quad S_{\text {config }}(-$ LiHEOF-7M $=2.36 R$, with $R$ being the ideal gas constant.

A comparison of the obtained XRD pattern is shown in Fig. 1a; here, the individual patterns of the different HEOs and Li(HEO)Fs are presented. All HEO and Li(HEO)F patterns show single-phase rocksalt structures, despite incorporating $\mathrm{Fe}$ and $\mathrm{Mn}$, which would produce multiple phases when oxidized. This could be additionally indicated by preparing the HEO-5M1 composition using NSP; the respective pattern shows a multi-phase structure, most probably caused by an oxidation of $\mathrm{Fe}^{2+}$ and $\mathrm{Mn}^{2+}$ during the NSP process. An analysis of the different phases of the multi-phase HEO-5M1 NSP material is found in Figure S1. During NSP, an aqueous precursor solution containing metal salts is nebulized into mist and then transferred to the hot zone of a tube furnace by nitrogen as carrier gas, finally to form the desired crystalline oxides at the elevated temperature. In this process, some ions, like $\mathrm{Mn}^{2+}$, are easily oxidized, creating a secondary phase. In contrast, ball milling using proper conditions can be done at room temperature and in an inert atmosphere (argon), so it can be easier to maintain the valences of metal ions during the synthesis process. Figure $1 b$ shows a magnification of the (200) reflection. A shift of the reflection can be identified, which corresponds to an expanse or reduction of the unit cell. The incorporation of bigger-sized ions should increase the lattice parameters, therefore leading to a reduction of the $2 \theta$ angle, while the introduction of smaller-sized ions reduces the size, leading to larger $2 \theta$ values. This trend is observed in Fig. $1 \mathrm{~b}$, based on the ionic radii of the incorporated ions (high-spin configuration assumed, since oxygen is a weak ligand following the spectrochemical series) [32-35]. Using HEO-5M1 as reference, it can be observed that the replacement of $\mathrm{Cu}^{2+}(0.73 \AA)$ with $\mathrm{Fe}^{2+}(0.78 \AA)$ leads to an expansion of the lattice parameters and a reduction of the $2 \theta$ angle as expected (HEO-5M2). The subsequent reintroduction of $\mathrm{Cu}^{2+}$ (HEO-6M) leads to a shift to larger $2 \theta$ values (smaller lattice parameters) and for HEO-7M even larger $2 \theta$ are detected, due to the smaller size of $\mathrm{Mg}^{2+}$ $(0.72 \AA)$. The same trend and an additional shift of the Li(HEO)F compounds compared to the HEO materials are detected, since $\mathrm{F}^{-}(1.33 \AA)$ shows smaller diameter than $\mathrm{O}^{2-}(1.4 \AA)$ in anionic sublattice.

Figure $2 \mathrm{a}, \mathrm{b}$ shows the comparison of the HEO-7M and LiHEOF-7M refinement patterns; the refinement patterns for all other components are found in the supporting information (Figure S2). Due to the lower atomic number of Li compared to other metals, the (111) reflection of Li-containing systems becomes less intense [28]. The refinements show the same trend as explained above, the incorporation of Fe expands the lattice and the length of the $a$-axis (Fig. 2c), and the reintroduction of $\mathrm{Cu}$ reduces it again and the introduction of $\mathrm{Mg}$ even more. The same behavior could be observed for the Li(HEO)F compounds, which generally show smaller diameters due to small $\mathrm{F}$. Interestingly, the reduction of the unit cell after $\mathrm{Mg}$ incorporation is stronger for $\mathrm{Li}(\mathrm{HEO}) \mathrm{F}$ than for the pure HEO compounds. The fitting parameters are found in Table S1.

To further investigate the structural details of the materials, TEM analysis was carried out. Using HEO7M and LiHEOF-7M as example, the morphology of them depicts polycrystalline particles with sizes 
Figure 1 a Comparison of XRD patterns of as-prepared HEOs and Li(HEO)Fs synthesized by ball-milling and NSP (indicated in the figure) method. While the NSP prepared HEO shows multiple phases, the ball-milled samples indicate single phases.

b Comparison of the (200) reflection position. The shifts can be related to the different incorporated ions and lattice parameters.
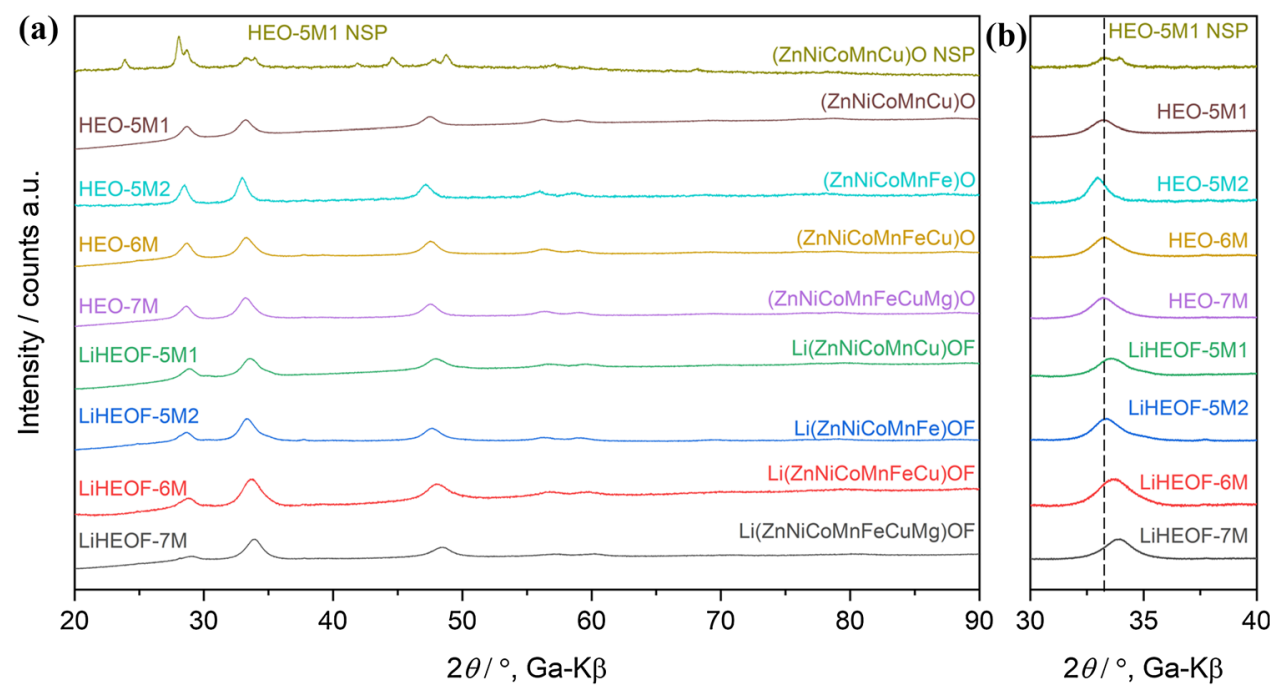

Figure 2 Refinement of a the HEO-7M and $\mathbf{b}$ the LiHEOF7M pattern. c Refined $a$-axis length and unit cell volume of the different compounds.
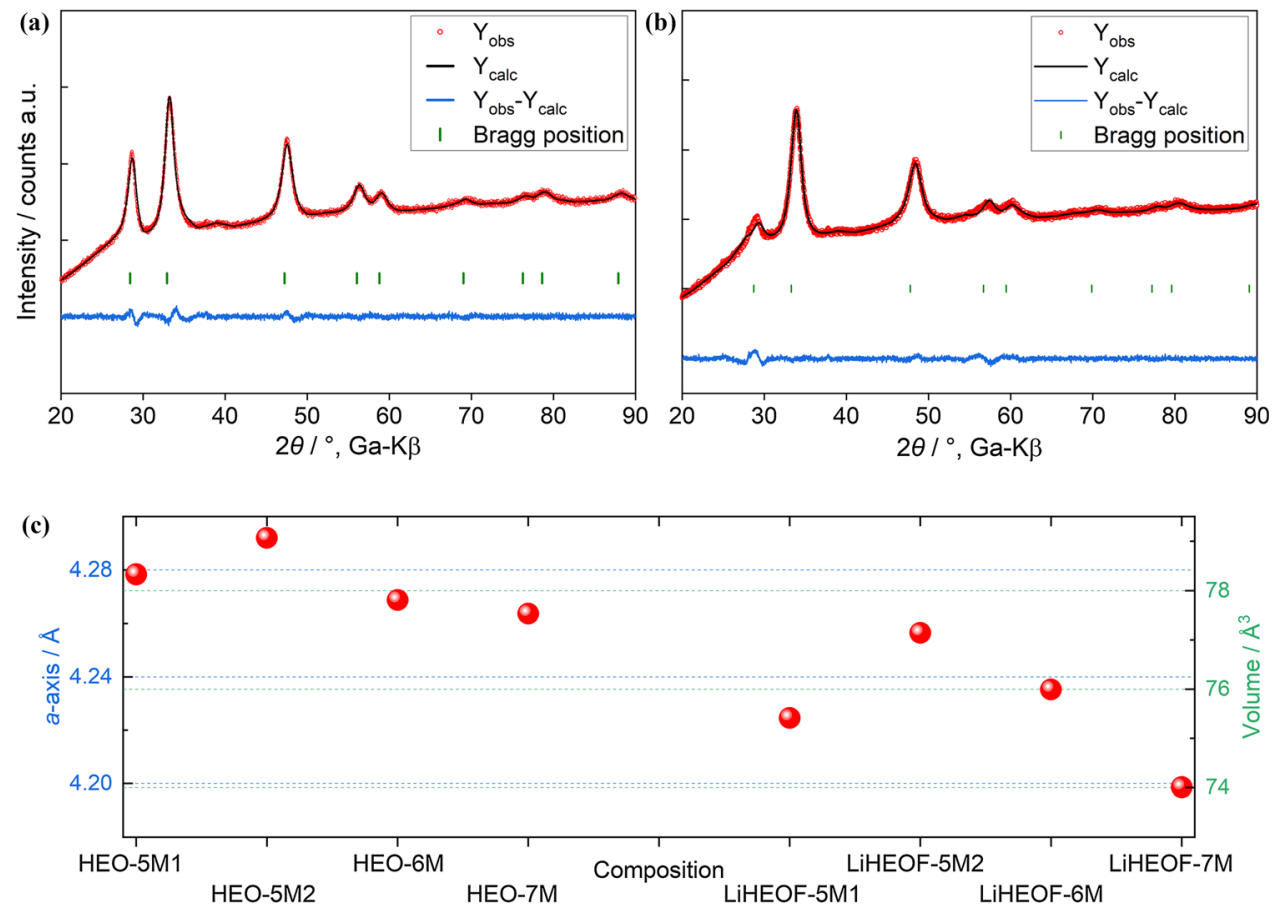

ranging from tens to hundreds of nanometers, as shown in Figure S3. Figure 3 shows high-resolution TEM (HR-TEM) micrographs, revealing a high crystallinity of the prepared HEO-7M compound. Figure $3 b$ shows a higher magnification of the area indicated with a white rectangle in Fig. 3a. The circled areas in Fig. $3 b$ correspond to the (111) (red) and (200) (yellow) lattice planes of the rock-salt structure. The diffraction rings for the rock-salt structure, in accordance with XRD measurements, could be further detected using selected area diffraction (SAED) in Fig. 3c. The crystallite sizes detected during TEM investigations match with the sizes drawn out of the refinement data, using the FWHM-based Scherrer equation. The calculated crystallize sizes amount to 11-20 nm; a TEM micrograph with highlighted particles supports this calculation (Figure S4).

Figure 4 shows scanning TEM (STEM)-EDX map of HEO-7M. All the constituent elements are homogeneously distributed in the whole material, without any segregation or clustering of single elements, in the respective magnification. Uniform distribution of 

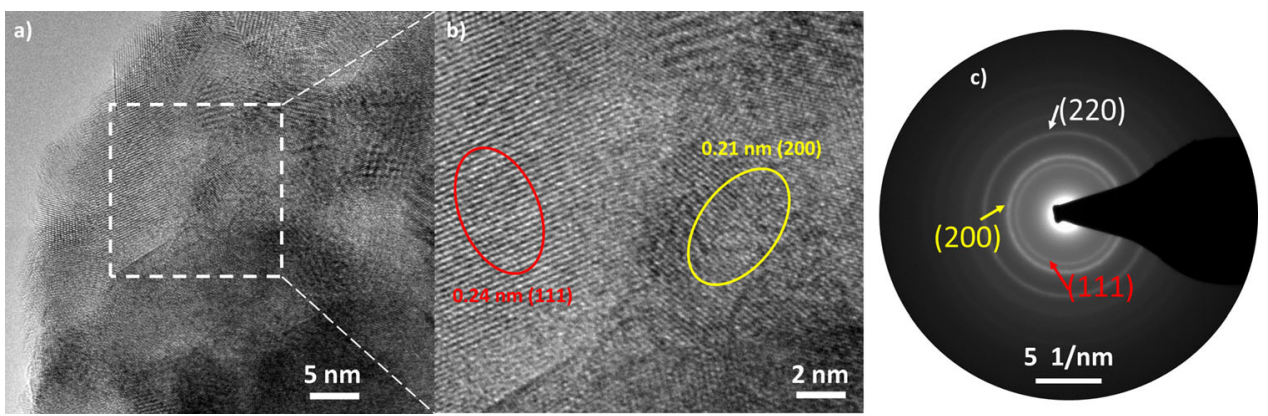

Figure 3 a HR-TEM of HEO-7M. b Magnified TEM image with crystal lattices of HEM-7 M. c SAED ring taken from HEM-7 M. The yellow and red circles indicate the (111) and (200) diffraction plane with lattice spacings of 0.24 and $0.21 \mathrm{~nm}$, respectively.

every element would lead to highest possible configurational entropy. The synthesized materials can be considered as real single phase according to EDX, XRD and SAED results.

As explained, the HEO materials were ball milled with $\mathrm{LiF}$ in order to form $\mathrm{Li}(\mathrm{HEO}) \mathrm{F}$ compounds. This mechanochemical synthesis was explored previously [28]. Now, due to the possibility to include oxidationsensitive elements into the HEO, the potential number of $\mathrm{Li}(\mathrm{HEO}) \mathrm{F}$ compositions has also been increased considerably. Figure 5 shows HR-TEM, SAED and EDX measurements of LiHEOF-7M for comparison to Figs. 3 and 4. Figure 5a depicts a HRTEM micrograph with SAED rings as an inset. In general, it can be seen that the crystallinity has been significantly reduced compared to HEO-7M. This is indicated as well from the broad (200) diffraction ring in the SAED, pointed out by the yellow ring. We attribute the reduction of crystallinity to the increased ball-milling time compared to the pure HEO-7M compounds. Figure $5 b$ shows EDX measurements of LiHEOF-7M, which show a homogenous distribution of all elements, including the incorporated $\mathrm{F}$ ( $\mathrm{Li}$ cannot be displayed using EDX).

Mössbauer spectroscopy was performed to gather further information about the solid-state condition of the HEO-7M by screening the chemical environment of Fe. Since this technique is very sensitive to all

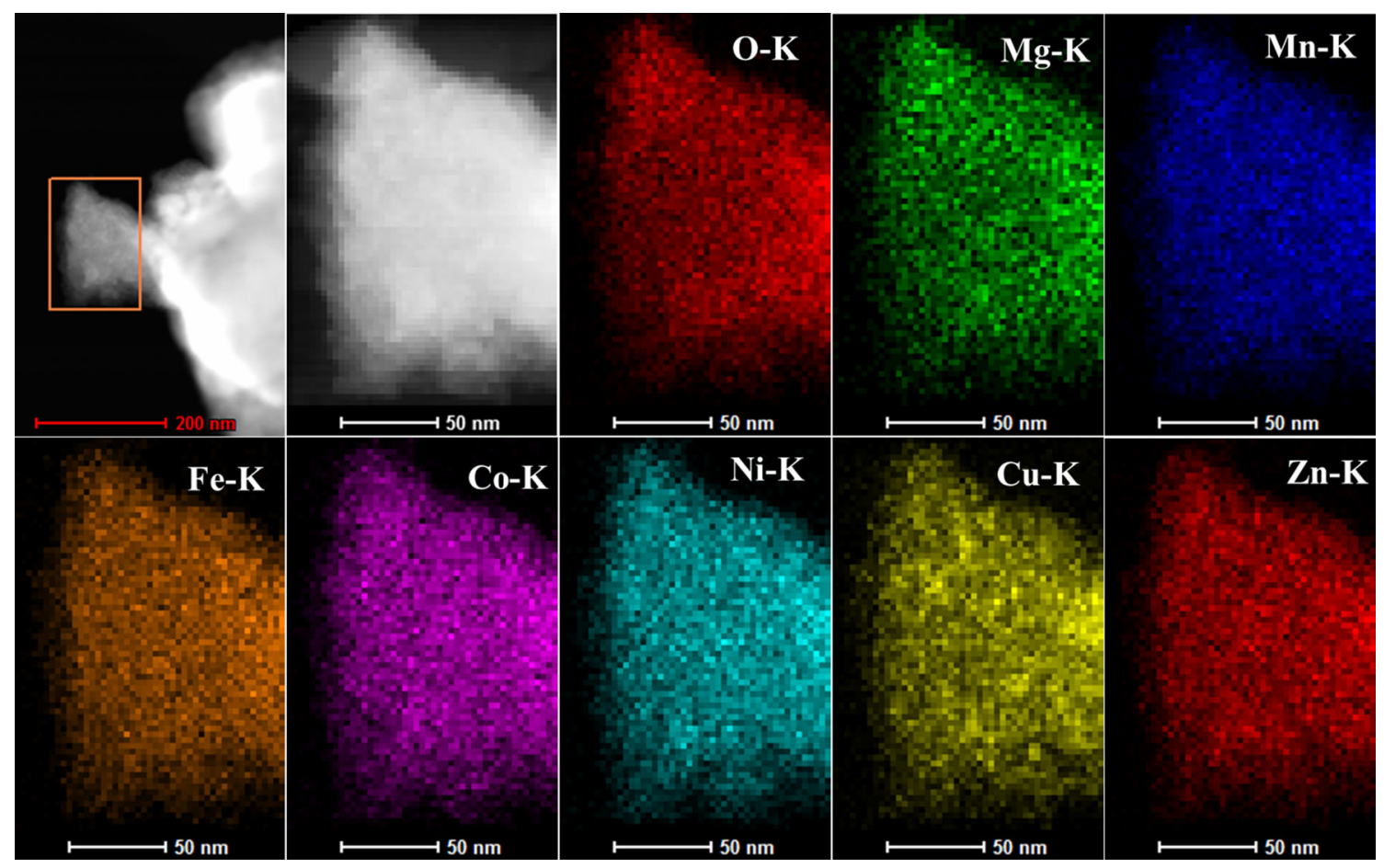

Figure 4 STEM-EDX mapping of HEO-7M. All constituent elements show homogenous distribution. 

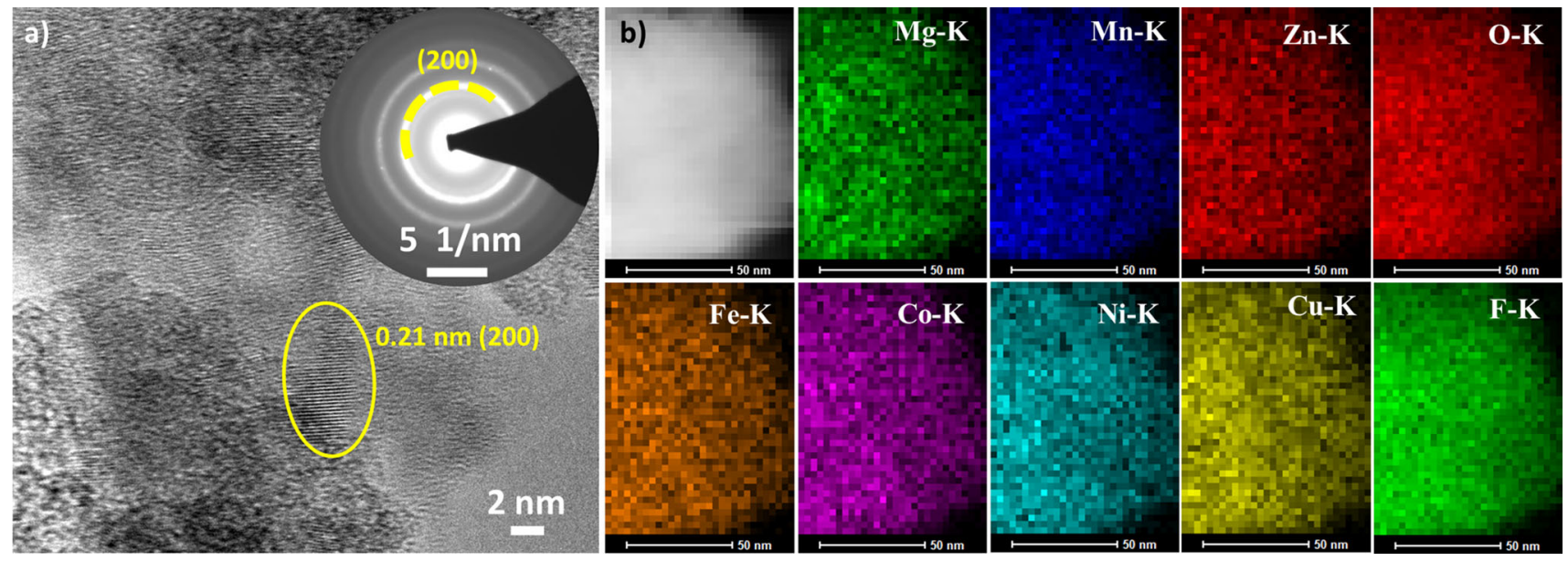

Figure 5 TEM investigation of LiHEOF-7M. a HR-TEM and SAED ring of LiHEOF-7M. $\mathbf{b}$ STEM-EDX mapping of LiHEOF-7M. The yellow circle indicates the (200) diffraction planes with a spacing of $0.21 \mathrm{~nm}$.

effects that have an influence on the electronic state of Fe, smallest changes in the chemical environment can be detected. If the material contains Fe in different conditions or environments, a splitting or shift of the Mössbauer peaks is expected. Figure 6 shows the Mössbauer data including the fit for $\mathrm{Fe}^{3+}$, displaying a material with a very homogenous environment for every included Fe atom, which is a strong indication for a solid solution condition for HEO-7M. The Mössbauer data could be fitted using one doublet spectrum, which corresponds to $\mathrm{Fe}^{3+}$ as the isomer shift is around $0.35 \mathrm{~mm} \mathrm{~s}^{-1}$ with respect to $\alpha-\mathrm{Fe}$. The

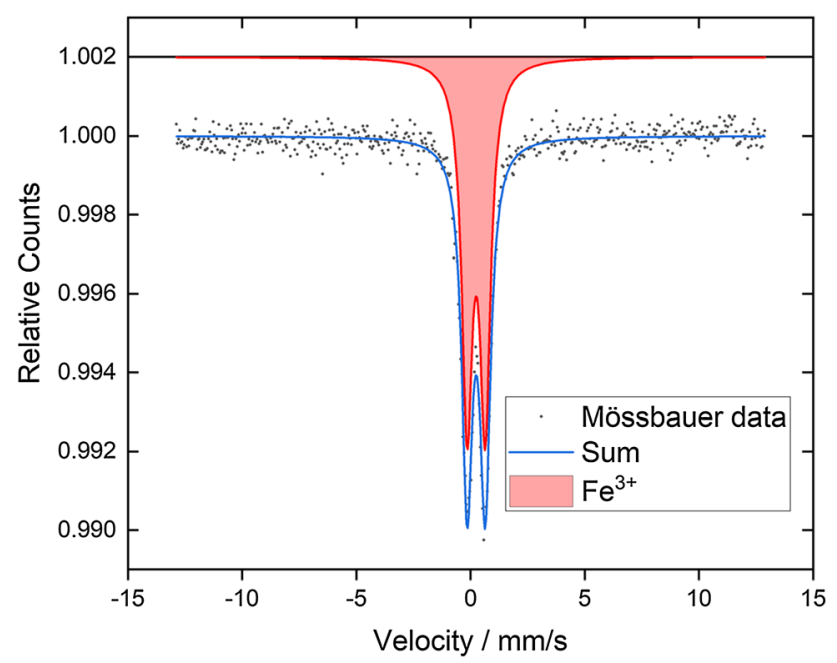

Figure 6 Mössbauer spectrum of HEO-7M. The isomer shift show $\mathrm{Fe}^{3+}$, which is homogenously distributed in the whole structure, indicating a solid solution state. Most probably, an internal disproportionation reaction between $\mathrm{Fe}^{2+}$ and $\mathrm{Cu}^{2+}$ leads to $\mathrm{Fe}^{3+}$ and $\mathrm{Cu}^{+}$. quadrupole split amounts to $0.79 \mathrm{~mm} \mathrm{~s}^{-1}$; in general, the compound is paramagnetic at room temperature [36].

The presence of $\mathrm{Fe}^{3+}$, instead of the utilized $\mathrm{Fe}^{2+}$ as in the precursor material, is unexpected, especially taken into account that a single-phase rock-salt structure is formed (average charge of cations in rock-salt: $2+$ ). Ions with higher valences tend to form spinel structures as explained in previous study [22]. To preserve a rock-salt structure with incorporated higher valence ions, a charge compensation has to occur to preserve the average charge of $2+$. An internal oxidation from $\mathrm{Fe}^{2+}$ to $\mathrm{Fe}^{3+}$ is only possible when another ion is reduced from a $2+$ state to $1+$ or when vacancies in the lattice occur. The only incorporated element capable of undergoing this reduction is $\mathrm{Cu}$; in fact, many different examples are reported in the literature where $\mathrm{Cu}^{+}$is being formed in a crystal structure [37, 38]. The internal disproportionation from $\mathrm{Fe}^{2+}$ and $\mathrm{Cu}^{2+}$ to $\mathrm{Fe}^{3+}$ and $\mathrm{Cu}^{+}$ leads to the observed Mössbauer results and can also be detected in the refined XRD pattern (Fig. 2c). While the $2+$ metal ions have very similar ionic radii (high-spin, octahedral coordinated: $\mathrm{Cu}^{2+}: 0.73 \AA$, $\mathrm{Fe}^{2+}: 0.78 \AA, \mathrm{Zn}^{2+}: 0.74 \AA, \mathrm{Co}^{2+}: 0.75 \AA, \mathrm{Ni}^{2+}: 0.69 \AA$, $\mathrm{Mg}^{2+}: 0.72 \AA$, except $\mathrm{Mn}^{2+}: 0.83 \AA$ ), $\mathrm{Fe}^{3+}$ shows a smaller ionic radius of $0.65 \AA$. At the same time, $\mathrm{Cu}^{+}$ is not much larger $(0.77 \AA$ ). Therefore, a material configuration including $\mathrm{Fe}^{2+}$ and $\mathrm{Cu}^{2+}$ is expected to show a larger unit cell (due to a larger average ionic radius) than a material including $\mathrm{Fe}^{3+}$ and $\mathrm{Cu}^{+}$. Compared to presented compounds containing $\mathrm{Cu}$ and Fe, HEO-5M2 and LiHEOF-5M2 do not introduce 
Figure 7 XPS spectrum of $\mathrm{Cu} 2 p$ (left) and $\mathrm{Cu}$ LMM (right) Auger spectrum of HEO-7M.

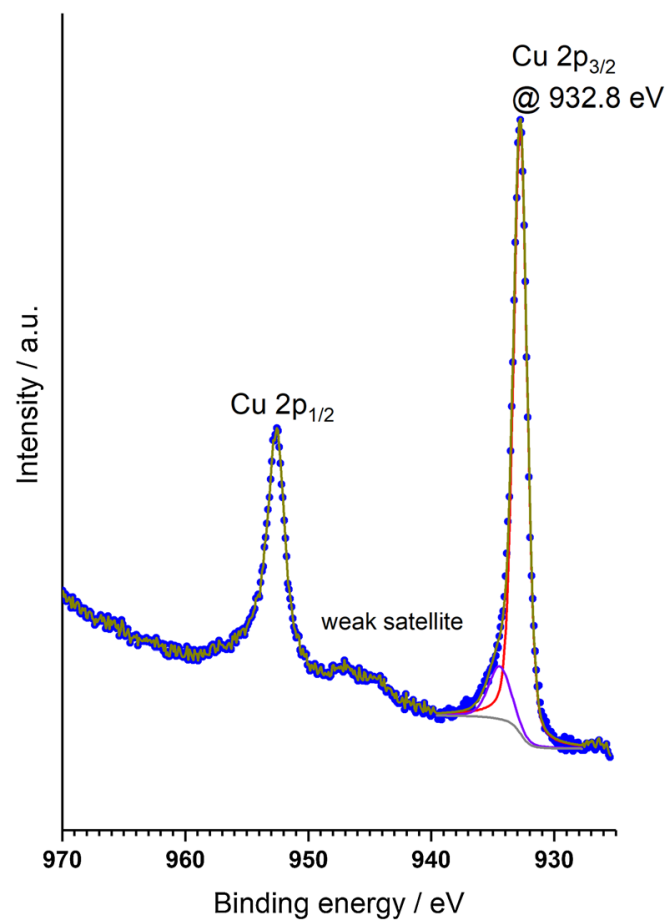

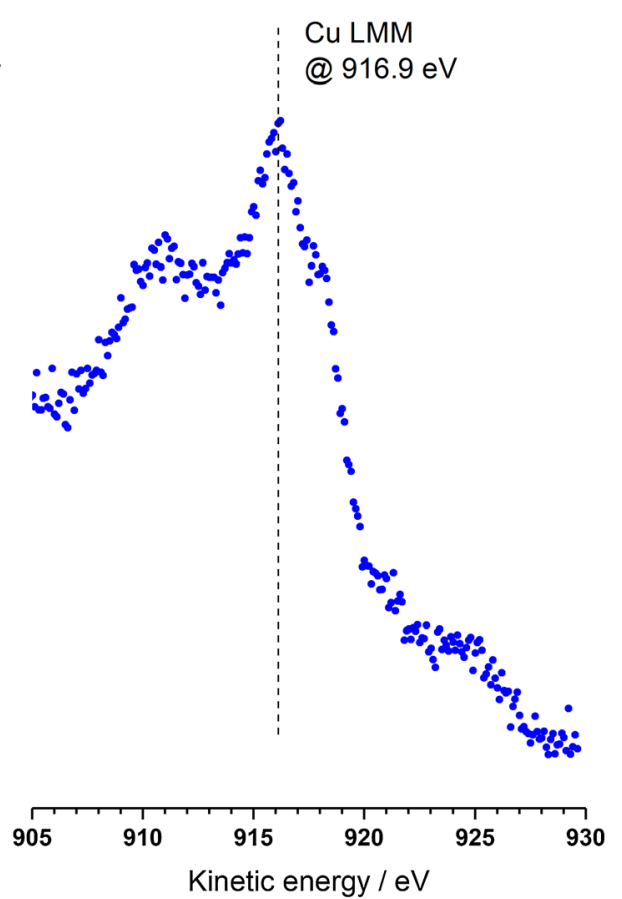

$\mathrm{Cu}^{2+}$ and therefore no disproportionation reaction can occur; the reduced size of the unit cell should not be observed in these cases. Figure $2 c$ shows that these compounds are indeed showing exceptional large unit cells, which can now be explained following the argumentation of an internal disproportionation reaction between $\mathrm{Cu}^{2+}$ and $\mathrm{Fe}^{2+}$.

In order to verify this assumption, the oxidation state of $\mathrm{Cu}$ was investigated by X-ray photoelectron spectroscopy (XPS). A reduced oxidation state (compared to $2+$ ) was expected to match with the presented theory. The $\mathrm{Cu} 2 p$ XPS and $\mathrm{Cu}$ LMM Auger spectrum of HEO-7M in Fig. 7 show the main $\mathrm{Cu} 2 p_{3 / 2}$ peak at $932.8 \mathrm{eV}$, a very weak satellite structure (at 944.2 and $946.8 \mathrm{eV}$ ) and a Cu LMM peak at $916.9 \mathrm{eV}$ that according to the literature [39], can be assigned to a $\mathrm{Cu}^{1+}$ state. The minor $\mathrm{Cu} 2 p_{3 / 2}$ peak at $934.5 \mathrm{eV}$ can be assigned to a slight formation of surface copper hydroxide due to treatment at air. These findings support the theory about the internal disproportionation reaction.

\section{Conclusion}

A mechanochemical synthesis route could be presented, which allows to incorporate redox-sensitive ions in single-phased rock-salt-structured high- entropy materials. This synthesis approach inhibits an oxidation during synthesis, therefore extends the choice of applicable elements and repeals the limitation to $\left(\mathrm{Co}_{0.2} \mathrm{Ni}_{0.2} \mathrm{Cu}_{0.2} \mathrm{Zn}_{0.2} \mathrm{Mg}_{0.2}\right) \mathrm{O}$. No charge compensating components like $\mathrm{Li}$ are needed. Internal disproportionation reactions can occur, but do not change the average charge of the cationic or anionic sublattice and therefore do not trigger a structural change to keep charge neutrality. We expect that countless further compositions for various applications can be prepared following this approach, widening the area of application for high-entropy materials.

\section{Acknowledgements}

L.L., Y.C. and J.W. acknowledge financial support from the China Scholarship Council (CSC). D.S., Q.W. and B.B. appreciate the support through EnABLES, a project funded by the Europeans Union's Horizon 2020 research and innovation program under grant agreement no. 730957. P.A. acknowledges the Ministry of Science, Research and Arts of the State of Baden Württemberg for funding research through the MERAGEM graduate School fellowship. The authors acknowledge the support from the Karlsruhe Nano Micro Facility (KNMF, www.knmf.kit.edu), a 
Helmholtz research infrastructure at Karlsruhe Institute of Technology (KIT, www.kit.edu). This work contributes to the research performed at CELEST (Center for Electrochemical Energy Storage Ulm-Karlsruhe). A.S. and H.H. acknowledge financial support from the Helmholtz Association and the Deutsche Forschungsgemeinschaft (HA 1344/43-1). The financial support of K-Alpha + by the Federal Ministry of Economics and Energy (BMWi) is acknowledged.

\section{Funding}

Open Access funding provided by Projekt DEAL.

\section{Compliance with ethical standards}

Conflict of interest The authors declare no conflict of interest.

Electronic supplementary material: The online version of this article (https://doi.org/10.1007/s108 53-020-05183-4) contains supplementary material, which is available to authorized users.

Open Access This article is licensed under a Creative Commons Attribution 4.0 International License, which permits use, sharing, adaptation, distribution and reproduction in any medium or format, as long as you give appropriate credit to the original author(s) and the source, provide a link to the Creative Commons licence, and indicate if changes were made. The images or other third party material in this article are included in the article's Creative Commons licence, unless indicated otherwise in a credit line to the material. If material is not included in the article's Creative Commons licence and your intended use is not permitted by statutory regulation or exceeds the permitted use, you will need to obtain permission directly from the copyright holder. To view a copy of this licence, visit http://creativecommons.org/licen ses/by/4.0/.

Electronic supplementary material: The online version of this article (https://doi.org/10.1007/s108 53-020-05183-4) contains supplementary material, which is available to authorized users.

\section{References}

[1] Murty BS, Yeh JW, Ranganathan S, Bhattacharjee PP (2019) High-entropy alloys. Elsevier, Amsterdam

[2] Sarkar A, Velasco L, Wang D et al (2018) High entropy oxides for reversible energy storage. Nat Commun 9:1-9. h ttps://doi.org/10.1038/s41467-018-05774-5

[3] Rost CM, Sachet E, Borman T et al (2015) Entropy-stabilized oxides. Nat Commun 6:1-8. https://doi.org/10.1038/nc omms 9485

[4] Sarkar A, Wang Q, Schiele A et al (2019) High-entropy oxides: fundamental aspects and electrochemical properties. Adv Mater 31:1806236. https://doi.org/10.1002/adma. 201806236

[5] Sarker P, Harrington T, Toher C et al (2018) High-entropy high-hardness metal carbides discovered by entropy descriptors. Nat Commun 9:1-10. https://doi.org/10.1038/s 41467-018-07160-7

[6] Bérardan D, Franger S, Meena AK, Dragoe N (2016) Room temperature lithium superionic conductivity in high entropy oxides. J Mater Chem A 4:9536-9541. https://doi.org/10. 1039/c6ta03249d

[7] Wang Q, Sarkar A, Li Z et al (2019) High entropy oxides as anode material for Li-ion battery applications: a practical approach. Electrochem Commun 100:121-125. https://doi. org/10.1016/j.elecom.2019.02.001

[8] Oses C, Toher C, Curtarolo S (2020) High-entropy ceramics. Nat Rev Mater 5:295-309. https://doi.org/10.1038/s41578019-0170-8

[9] Lee J, Urban A, Li X, Su D, Hautier G, Ceder G (2014) Unlocking the potential of cation-disordered oxides for rechargeable lithium batteries. Science 343:519-522. http s://doi.org/10.1126/science.1246432

[10] Clément RJ, Lun Z, Ceder G (2020) Cation-disordered rocksalt transition metal oxides and oxyfluorides for high energy lithium-ion cathodes. Energy Environ Sci 13:345-373. https://doi.org/10.1039/C9EE02803J

[11] Lun Z, Ouyang B, Kitchaev DA et al (2019) Improved cycling performance of Li-excess cation-disordered cathode materials upon fluorine substitution. Adv Energy Mater 9:1802959. https://doi.org/10.1002/aenm.201802959

[12] Ren S, Chen R, Maawad E et al (2015) Improved voltage and cycling for $\mathrm{Li}+$ intercalation in high-capacity disordered oxyfluoride cathodes. Adv Sci 2:1500128. https://doi. org/10.1002/advs.201500128

[13] Baur C, Chable J, Klein F, Chakravadhanula VSK, Fichtner M (2018) Reversible delithiation of disordered rock salt $\mathrm{LiVO}_{2}$. ChemElectroChem 5:1484-1490. https://doi.org/10. 1002/celc.201800189 
[14] Chen K, Pei X, Tang L et al (2018) A five-component entropy-stabilized fluorite oxide. J Eur Ceram Soc 38:4161-4164. https://doi.org/10.1016/j.jeurceramsoc.2018. 04.063

[15] Djenadic R, Sarkar A, Clemens O et al (2017) Multicomponent equiatomic rare earth oxides. Mater Res Lett 5:102-109. https://doi.org/10.1080/21663831.2016.1220433

[16] Gild J, Samiee M, Braun JL et al (2018) High-entropy fluorite oxides. J Eur Ceram Soc 38:3578-3584. https://doi.org/ 10.1016/j.jeurceramsoc.2018.04.010

[17] Sarkar A, Loho C, Velasco L et al (2017) Multicomponent equiatomic rare earth oxides with a narrow band gap and associated praseodymium multivalency. Dalton Trans 46:12167-12176. https://doi.org/10.1039/c7dt02077e

[18] Sarkar A, Djenadic R, Wang D et al (2018) Rare earth and transition metal based entropy stabilised perovskite type oxides. J Eur Ceram Soc 38:2318-2327. https://doi.org/10. 1016/j.jeurceramsoc.2017.12.058

[19] Jiang S, Hu T, Gild J et al (2018) A new class of highentropy perovskite oxides. Scr Mater 142:116-120. https://d oi.org/10.1016/j.scriptamat.2017.08.040

[20] Sharma Y, Musico BL, Gao X et al (2018) Single-crystal high entropy perovskite oxide epitaxial films. Phys Rev Mater 2:060404. https://doi.org/10.1103/PhysRevMaterials. 2.060404

[21] Dąbrowa J, Stygar M, Mikula A et al (2018) Synthesis and microstructure of the $(\mathrm{Co}, \mathrm{Cr}, \mathrm{Fe}, \mathrm{Mn}, \mathrm{Ni}) 3 \mathrm{O} 4$ high entropy oxide characterized by spinel structure. Mater Lett 216:32-36. https://doi.org/10.1016/j.matlet.2017.12.148

[22] Wang J, Stenzel D, Azmi R et al (2020) Spinel to rock-salt transformation in high entropy oxides with Li incorporation. Electrochem 1:60-74. https://doi.org/10.3390/electroche m1010007

[23] Bérardan D, Franger S, Dragoe D et al (2016) Colossal dielectric constant in high entropy oxides. Phys Status Solidi Rapid Res Lett 10:328-333. https://doi.org/10.1002/pssr. 201600043

[24] Sarkar A, Djenadic R, Usharani NJ et al (2017) Nanocrystalline multicomponent entropy stabilised transition metal oxides. J Eur Ceram Soc 37:747-754. https://doi.org/10.10 16/j.jeurceramsoc.2016.09.018

[25] Biesuz M, Spiridigliozzi L, Dell'Agli G et al (2018) Synthesis and sintering of $(\mathrm{Mg} \mathrm{Co}, \mathrm{Ni}, \mathrm{Cu}, \mathrm{Zn}) \mathrm{O}$ entropy-stabilized oxides obtained by wet chemical methods. J Mater Sci 53:8074-8085. https://doi.org/10.1007/s10853-018-216 8-9

[26] Mao A, Quan F, Xiang HZ et al (2019) Facile synthesis and ferrimagnetic property of spinel $(\mathrm{CoCrFeMnNi})_{3} \mathrm{O}_{4}$ highentropy oxide nanocrystalline powder. J Mol Struct 1194:11-18. https://doi.org/10.1016/j.molstruc.2019.05.073
[27] Mao A, Xiang HZ, Zhang ZG et al (2019) Solution combustion synthesis and magnetic property of rock-salt $\left(\mathrm{Co}_{0.2} \mathrm{Cu}_{0.2} \mathrm{Mg}_{0.2} \mathrm{Ni}_{0.2} \mathrm{Zn}_{0.2}\right) \mathrm{O}$ high-entropy oxide nanocrystalline powder. J Magn Magn Mater 484:245-252. https://d oi.org/10.1016/j.jmmm.2019.04.023

[28] Wang Q, Sarkar A, Wang D et al (2019) Multi-anionic and cationic compounds: new high entropy materials for advanced Li-ion batteries. Energy Environ Sci 12:2433-2442. https://doi.org/10.1039/c9ee00368a

[29] Parry KL, Shard AG, Short RD, White RG, Whittle JD, Wright A (2006) ARXPS characterisation of plasma polymerised surface chemical gradients. Surf Interface Anal 38:1497-1504. https://doi.org/10.1002/sia.2400

[30] Scofield JH (1976) Hartree-Slater subshell photoionization cross-sections at 1254 and $1487 \mathrm{eV}$. J Electron Spectros Relat Phenom 8:129-137. https://doi.org/10.1016/0368-204 8(76)80015-1

[31] Tanuma S, Powell CJ, Penn DR (2011) Calculations of electron inelastic mean free paths. IX. Data for 41 elemental solids over the $50 \mathrm{eV}$ to $30 \mathrm{keV}$ range. Surf Interface Anal 43:689-713. https://doi.org/10.1002/sia.3522

[32] Shannon RD (1976) Revised effective ionic radii and systematic studies of interatomic distances in halides and chalcogenides. Acta Crystallogr A 32:751-767. https://doi. org/10.1107/S0567739476001551

[33] Burns RG (1993) Mineralogical applications of crystal field theory. Cambridge University Press, Cambridge

[34] Newman DJ (1977) Ligand ordering parameters. Aust J Phys 30:315-324. https://doi.org/10.1071/ph770315

[35] Shimura Y (1988) A quantitative scale of the spectrochemical series for the mixed ligand complexes of $\mathrm{d}^{6}$ metals. Bull Chem Soc Jpn 61:693-698. https://doi.org/10.1246/bcsj.61. 693

[36] Menil F (1985) Systematic trends of the ${ }^{57} \mathrm{Fe}$ Mössbauer isomer shifts in $\left(\mathrm{FeO}_{\mathrm{n}}\right)$ and $\left(\mathrm{FeF}_{\mathrm{n}}\right)$ polyhedra. Evidence of a new correlation between the isomer shift and the inductive effect of the competing bond $\mathrm{T}-\mathrm{X}(\rightarrow \mathrm{Fe})$ (where $\mathrm{X}$ is $\mathrm{O}$ or $\mathrm{F}$ and $\mathrm{T}$ any element with a formal positive charge). J Phys Chem Solids 46:763-789. https://doi.org/10.1016/0022-369 7(85)90001-0

[37] Sen D, Kim CW, Heo NH, Seff K (2014) Introducing copper ions into zeolite $\mathrm{Y}$ by the thallous ion exchange method: single crystal structure of $\left|\mathrm{Cu}_{21.6} \mathrm{Tl}_{39.2}\right|\left[\mathrm{Si}_{121} \mathrm{Al}_{71} \mathrm{O}_{384}\right]$-FAU. J Porous Mater 21:321-330. https://doi.org/10.1007/s10934013-9777-0

[38] Morishita K, Suto H, Kamiya I (2015) The reduction of $\mathrm{Cu}^{2+}$ and crystal growth processes during colloidal synthesis of $\mathrm{Cu}_{2} \mathrm{ZnSnS}_{4}$ nanoparticles. In: 2015 IEEE 42nd photovoltaic specialist conference (PVSC), New Orleans, pp 1-4. https://doi.org/10.1109/pvsc.2015.7356364 
[39] Biesinger MC (2017) Advanced analysis of copper x-ray photoelectron spectra. Surf Interface Anal 49:1325-1334. h ttps://doi.org/10.1002/sia.6239
Publisher's Note Springer Nature remains neutral with regard to jurisdictional claims in published maps and institutional affiliations. 